\title{
The Effect of Sodium Taurocholate on the
}

\section{Hepatic Metabolism of Sulfobromophthalein}

Sodium (BSP). The Role of Bile Flow

\author{
J. L. Boyer, R. L. Scheig, and G. KLATSKIn \\ From the Department of Medicine, Yale University School of Medicine, \\ New Haven, Connecticut 06510
}

A B S T R A C T The influence of bile salts on the hepatic metabolism of sulfobromophthalein sodium (BSP) was studied in the perfused rat liver. During sodium taurocholate infusions, hepatic uptake of BSP from plasma was increased and appeared to be related to an enhanced transit of BSP from liver into bile. BSP-glutathione conjugation was not affected by the bile salt infusions, although bile salts inhibited the enzyme system in vitro.

The major effect of bile salts was to increase the BSP transport maximum ( Tm). When sodium taurocholate was infused in saline at a rate of $30 \mu$ moles $/ \mathrm{hr}$, both bile flow and the BSP Tm increased, and remained at peak levels of $1.5 \pm 0.12 \mu \mathrm{l} / \mathrm{min}$ per $\mathrm{g}$ liver and 21 $\pm 3.0 \mu \mathrm{g} / \mathrm{min}$ per $\mathrm{g}$ liver, respectively. In contrast, during saline infusion alone both levels were significantly lower $(1.06 \pm 0.17 \mu \mathrm{l} / \mathrm{min}$ per $\mathrm{g}$ liver and $15.8 \pm 4.16$ $\mu \mathrm{g} / \mathrm{min}$ per $\mathrm{g}$ liver, respectively), and both fell progressively after the 2 nd $\mathrm{hr}$ of perfusion. This decline in bile flow and BSP Tm was associated with a decrease in biliary bile salt excretion and was reversed by adding bile salts to the perfusate. Since the biliary concentration of $\mathrm{BSP}$ remained within a narrow range in all experiments, the BSP Tm was primarily determined by the rate of bile flow.

Dependence of BSP Tm on the rate of bile production was further confirmed by changing the temperature of the perfusate during a constant infusion of taurocholate. BSP Tm paralleled temperature-induced changes in bile flow irrespective of changes in the level of bile salt excretion.

Since the biliary concentration of BSP remained within a narrow range in all experiments, the concen-

This study was presented in part at the annual meeting of the American Association for the Study of Liver Disease, 30-31 October 1968, Chicago (Gastroenterology. 56: 402).

Received for publication 26 May 1969 and in revised form 18 July 1969. trating capacity for BSP in bile may be the major limiting factor in BSP transport. Thus two independent factors appear to determine the BSP Tm: the bile BSP concentration, and the rate of bile production.

Because taurocholate enhanced BSP transport only when it increased bile production, its effect on the BSP $\mathrm{Tm}$ appears to be attributable to its choleretic properties.

\section{INTRODUCTION}

The removal of sulfobromophthalein sodium (BSP) from plasma and its excretion into bile involves hepatic uptake, storage, glutathione conjugation, and transport of the dye into the canaliculi (1-5). As in the case of other organic anions, such as bilirubin, fluorescein, and Indocyanin Green, transport across the canalicular membrane is the rate-limiting step in this process (6-9). Many disease processes $(10,11)$, alterations in physiologic states $(12,13)$, and administration of drugs and hormones (14-16) affect the BSP transport maximum ( $\mathrm{Tm}$ ). However, the factors which determine the Tm are uncertain although conjugation with glutathione is believed to be one of these $(2,17)$.

Recently, it has been shown that infusion of bile salts increases the BSP Tm (18-20). This observation suggests that bile salts may play an important role in regulating the biliary excretion of BSP and other organic anions.

To investigate the mechanisms involved in enhancement of the BSP Tm induced by bile salts, we have studied their effects on BSP metabolism in the isolated perfused rat liver. Our results indicate that bile salts increase BSP transport by stimulating bile flow.

\section{METHODS}

Materials. Fraction $\mathrm{V}$ bovine serum albumin was obtained from Nutritional Biochemicals Corporation, Cleve- 
land, Ohio. A 10\% dextrose solution, USP, used as a source of glucose, was obtained from Cutter Laboratories, Berkeley, Calif. Bromsulphalein (BSP), $50 \mathrm{mg} / \mathrm{ml}$, was purchased from Hynson, Westcott \& Dunning, Inc., Baltimore, Md. The sodium taurocholate preparation, obtained from Mann Research Laboratories, contained only two minor impurities as determined by thin-layer chromatography.

Rat liver perfusion. Sprague-Dawley rats weighing 300$400 \mathrm{~g}$ (Charles River Breeding Laboratory, Wilmington, Mass.) and maintained on Purina lab chow ad lib. served as liver and blood donors. The perfusion technique used was essentially that described by Miller, Bly, Watson, and Bale (21). Two parts heparinized whole rat blood filtered through gauze were diluted with one part Krebs-Ringer bicarbonate buffer containing $5 \mathrm{~g}$ albumin and $100 \mathrm{mg}$ glucose $/ 100 \mathrm{ml}$, and adjusted to $\mathrm{pH} 7.45$ with $1 \mathrm{~N} \mathrm{NaOH}$ before use. The perfusate, which had a hematocrit of $16-22 \%$ (average $20 \%$ ), was oxygenated with a mixture of $5 \%$ $\mathrm{CO}_{2}$ and $95 \%$ oxygen at a gas flow rate of $250 \mathrm{ml} / \mathrm{min}$, and maintained at a constant temperature of $37^{\circ} \mathrm{C}$. In each experiment, $100 \mathrm{ml}$ of oxygenated blood-buffer mixture was perfused through the portal vein via a glass cannula at a hydrostatic pressure of $14 \mathrm{~cm}$. Bile was collected over 30 min intervals throughout the study in small tubes immersed in an ice bath protected against exposure to light. Hepatic blood flow, monitored each half hour, ranged from 22 to 32 $\mathrm{ml} / \mathrm{min}$. To avoid the use of livers with impaired secretory function attributable to anoxia, donor livers were rejected for perfusing if bleeding occurred before their removal, if the portal vein collapsed before cannulation, and if perfusion could not be initiated within $8 \mathrm{~min}$ after ligation of the portal vein. Also eliminated were experiments in which blood flow was not maintained within $20 \%$ of the rate attained after the 1 st $\mathrm{hr}$ of the perfusion. It was found that the $\mathrm{pH}$ of the perfusate fell from 7.45 to 7.0 over a $5 \mathrm{hr}$ period despite maintenance of the $\mathrm{pCO}_{2}$ at $40 \mathrm{~mm} \mathrm{Hg}$. Since this occurred in both experimental and control perfusions, it was discounted as a factor in the results obtained.

Experimental design. The transport of BSP from plasma into liver and bile was studied in 21 perfusion experiments. An infusion of $\mathrm{BSP}$ at a constant rate of $378 \mu \mathrm{g} / \mathrm{min}$ was begun $30 \mathrm{~min}$ after the start of each perfusion and was maintained for 4.5 or $5 \mathrm{hr}$. A progressive rise in the concentration of the perfusate BSP was observed in all studies.

In the initial experiments, we studied BSP transport during a constant infusion of sodium taurocholate $(30 \mu \mathrm{moles} /$ $\mathrm{hr}$ ). Five perfusions were performed and the results compared with five control studies. In five others, the infusion of taurocholate was begun either 3.5 or $4 \mathrm{hr}$ after beginning the study. All of these perfusions were performed at $37^{\circ} \mathrm{C}$.

In a second set of experiments, the temperature of the perfusate was altered to study BSP transport at varying rates of bile flow. Sodium taurocholate was infused as described above, to dissociate direct effects of bile salt on hepatic metabolism from its choleretic properties. BSP was infused at a rate of $392 \mu \mathrm{g} / \mathrm{min}$. In three perfusions, the temperature was maintained at $40^{\circ} \mathrm{C}$ during the first $2 \mathrm{hr}$, diminished to room temperature $\left(25^{\circ}-30^{\circ} \mathrm{C}\right)$ from 2 to $4 \mathrm{hr}$, and again raised to $40^{\circ} \mathrm{C}$ for the final hour. In three other perfusions, hypothermia was maintained for the final hour but the bile salt infusion was doubled ( $60 \mu \mathrm{moles} / \mathrm{hr}$ ) from $3.5 \mathrm{hr}$ to completion of the $5 \mathrm{hr}$ perfusion.

Measurements of bile volume and BSP content were made on each $30 \mathrm{~min}$ collection of bile in all studies. The total bile acid content of bile was estimated in each consecutive col- lection, and $1 \mathrm{ml}$ of perfusate was analyzed for BSP at 1.5 , $2.5,3$, and $5 \mathrm{hr}$.

The statistical significance of differences between groups was calculated by the paired $t$ test (22).

$B S P$ analysis. $10 \mu \mathrm{l}$ of each half-hour collection of bile was thoroughly mixed with $10.0 \mathrm{ml}$ saline to achieve concentrations of BSP that could be measured spectrophotometrically. Diluted bile samples and $0.5 \mathrm{ml}$ aliquots of perfusate were analyzed for BSP by the method of Seligson, Marino, and Dodson (23), by use of a Zeiss PM QII spectrophotometer at $580 \mathrm{~m} \mu$. Neither albumin nor hemoglobin changed the molar extinction coefficient of BSP. Although dilution of dog bile has been found to reduce the recovery of BSP (7), quantitative recovery of BSP standards (25 $\mathrm{mg} / \mathrm{ml}$ rat bile) was achieved in the present studies.

Liver weights. The liver weight used in all calculations was the weight of the untrimmed cannulated liver before infusion minus the weight of the cannula and excess tissue removed at the end of the experiment.

Total bile acid estimates. Total bile acids were determined quantitatively by Javitt and Emerman's modification (24) of the method of Iwata and Yamasaki for quantitative bile acid analysis (25), using hydroxysteroid dehydrogenase obtained from Pseudomonas testeroni (Worthington Biochemical Corporation, Freehold, N. J.). Several further modifications were made for purposes of this study. Dried bacterial cells (250 $\mathrm{mg}$ ) were suspended in distilled water and disrupted with a Sonifier Cell Disruptor, model W185D, using a No. 3 position at $70 \mathrm{w}$ for $10 \mathrm{~min}$. The temperature was kept below $5^{\circ} \mathrm{C}$ by sonicating only every other $15 \mathrm{sec}$ in a salted ice bath. The $\mathrm{NH}_{4} \mathrm{SO}_{4}$ precipitate was prepared as previously described (24). Immediately before use, one-fifth of the precipitate was resuspended in $10 \mathrm{ml}$ distilled water and centrifuged at $18,000 \mathrm{~g}$ in a Sorvall centrifuge at $4^{\circ} \mathrm{C}$ for $20 \mathrm{~min}$ to clarify the solution. The incubation mixture contained $0.5 \mathrm{ml}$ enzyme, $0.25 \mathrm{ml} 5 \mathrm{~mm}$ nicotinamide adenine dinucleotide (NAD), $0.5 \mathrm{ml} 1 \mathrm{M}$ hydrazine (Fairmount Chemical Co., Inc., Newark, N. J.) and $1.75 \mathrm{ml} 0.1 \mathrm{M}$ $\mathrm{K}_{2} \mathrm{HPO}_{4}, \mathrm{pH}$ 9.4. After adding bile or bile acid standard in 10 - or $20-\mu 1$ amounts, the reaction mixture was incubated at room temperature for $45 \mathrm{~min}$. The optical density was measured at exactly $45 \mathrm{~min}$, and the values for enzyme and bile acid blank were subtracted. All determinations were made at $340 \mathrm{~m} \mu$ with a Zeiss spectrophotometer. The enzyme blank was read at the same time as the sample since a reaction between hydrazine and NAD resulted in a slow continuous increment in the optical density reading. Mean recovery of $0.3 \mu$ moles of a desoxycholic acid standard was $98.7 \pm 1.2 \%$.

BSP conjugating activity. Two studies were performed to determine if the activity of the enzyme that conjugates BSP with glutathione was altered by the perfusion technique or by the infusion of sodium taurocholate. (a) Taurocholate in saline, or saline alone, was infused for $5 \mathrm{hr}$ during perfusion of a rat liver. Lobes were removed from the livers at $0,2.5$, and $5 \mathrm{hr}$, and the BSP glutathione-conjugating enzyme was prepared and assayed as described by Goldstein and Combes (26) and modified by Klaassen and Plaa (27). Preliminary studies indicated that the enzyme activity in different lobes of the rat liver were comparable. The activity of the enzyme from the livers of 10 rats that were not perfused was also determined. (b) In a second experiment, sodium taurocholate was added to the pyrophosphate buffer contained in the enzyme reaction mixture to determine the effect of increasing amounts of bile salt on the in vitro BSP conjugating activity of normal rat liver. $1,10,25,50$, 
and $100 \mu$ moles of sodium taurocholate were added, and the assays were carried out in duplicate. No change in $\mathrm{pH}$ was observed in any of these reaction mixtures.

BSP metabolites. Separation of the metabolites of BSP in bile was performed on Merck precoated cellulose $F$ plates, essentially as described by Whelan and Plaa (28). For identification purposes, $1.0 \mu \mathrm{l}$ of a BSP standard $(25 \mu \mathrm{g} / \mu \mathrm{l})$ and $1.0 \mu \mathrm{l}$ of the bile sample were applied at the origin with a $1.0 \mu 1$ pipette. For quantitative analysis of BSP and its conjugataes, $15 \mu \mathrm{l}$ of bile were applied. A Wood's lamp was used to identify BSP and its metabolites (one large and three small fluorescent spots were observed in addition to the area containing the unconjugated BSP). The spot corresponding to unconjugated $B S P$ was scraped from the plate into a glass vial containing $1 \mathrm{ml}$ distilled water, while all the spots corresponding to the conjugates were transferred to a vial containing $5 \mathrm{ml}$ of distilled water. The BSP was eluted by shaking in a Dubnoff incubator at $37^{\circ} \mathrm{C}$ for $20 \mathrm{~min}$. The cellulose was then removed by centrifugation at 1200 rpm for $10 \mathrm{~min}$, and quantitative analysis of $0.5 \mathrm{ml}$ aliquots of the supernatant solution was performed as previously described. Total recoveries exceeded $90 \%$ in all instances. The spots that were applied for identification purposes were sprayed with ninhydrin, and the color developed at $100^{\circ} \mathrm{C}$ for 2-3 min to confirm the presence of the BSP metabolite. Final confirmation that the fluorescent spots were BSP was obtained by exposing the plate to ammonia fumes and observing the appearance of a dark purple color. Only the fluorescent spots developed color in the presence of ammonia. The per cent unconjugated BSP in a given sample was expressed as the ratio of unconjugated BSP to the total BSP content of the chromatographed sample.

Hepatic removal rate and hepatic content of $B S P$. Hepatic removal rate $(R)$ of $B S P$ from the perfusate was calculated from the equation: $R=I \pm$ plasma volume $\times \Delta p / \Delta t$, where $I=$ the infusion rate of $B S P$ and $\Delta p / \Delta t=$ the change in concentration of perfusate $\mathrm{BSP} / \mathrm{min}$. Plasma volume was determined from the hematocrit and perfusate volume. Hepatic content of BSP was determined by subtracting both the amount of BSP excreted into bile and that remaining in plasma from the total amount of BSP infused. Hepatic content was then expressed as a per cent of the total amount of infused BSP. Measurements of hepatic removal rate and hepatic content of BSP were made at 2.5 and $5 \mathrm{hr}$ during the perfusion.

\section{RESULTS}

Effect of bile salts on bile flow, BSP Tm, and biliary concentration of BSP. The volume of bile produced during each half hour reached a maximum level within the first $2 \mathrm{hr}$ in both control and taurocholate perfused livers (Fig. 1, lower graph). While the peak flow in controls was $1.06 \pm 0.17 \mu \mathrm{l} / \mathrm{min}$ per $\mathrm{g}$ liver and then declined thereafter, a significantly higher peak flow rate of $1.50 \pm 0.12 \mu \mathrm{l} / \mathrm{min}$ per $\mathrm{g}$ liver occurred during the sodium taurocholate infusion $(P<0.001)$, and was maintained for the duration of the study.

Marked differences in the biliary concentration of bile acids were observed in the two studies (Fig. 1, upper graph). For the sake of comparison, the in vivo bile acid concentration was measured in bile collected for 15 min after cannulation of the common bile duct in 10 intact male rats. This is shown as the zero time value in the figure $(32.5 \pm 5.4 \mu \mathrm{moles} / \mathrm{ml})$. The biliary con-

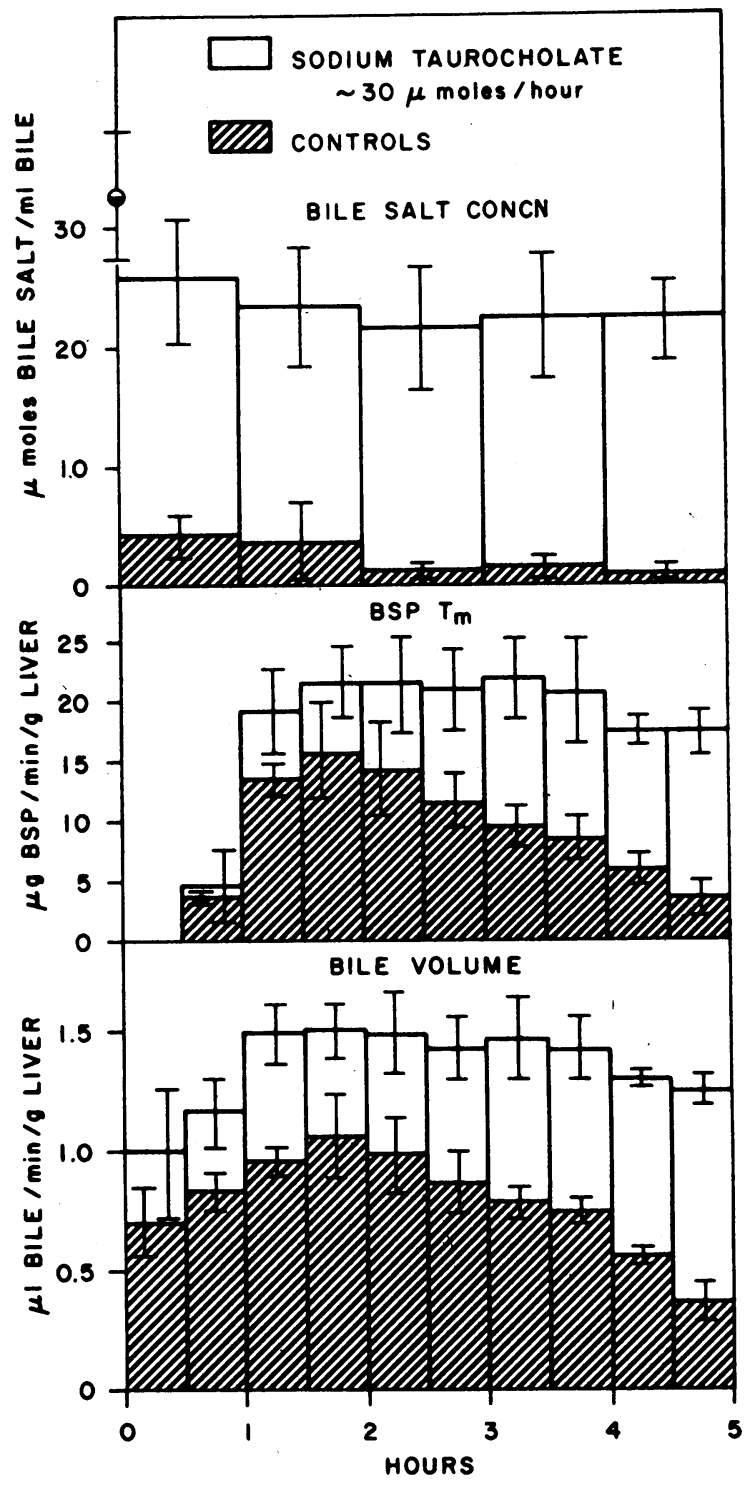

Figure 1 The effect of bile salt infusion on bile volume (lower graph), total bile salt concentration in bile (upper graph) and the BSP transport maximum ( Tm) (middle graph) in the perfused rat liver. The mean and standard deviation for each determination is represented for five control studies and five studies during sodium taurocholate infusion. Significant differences in bile flow were noted after the 1st half hour $(P<0.001)$ while differences in bile salt concentration in each hourly collection of bile were highly significant throughout the study $(P<0.001)$. Differences in the BSP Tm were significant by $2 \mathrm{hr}(P<$ $0.05)$ and highly significant after $2.5 \mathrm{hr}(P<0.001)$. The in vivo bile salt concentration in bile from normal intact rats was $32.5 \pm 5.4 \mu \mathrm{moles} / \mathrm{ml}$ and is included for comparison. It is represented by the half-shaded circle at zero time in the upper graph. 
centration of bile acids in control perfused livers was only one-fifth of this value within the 1 st $\mathrm{hr}$ of the perfusion, and remained at low levels thereafter. In contrast, during taurocholate infusion, the concentration remained at levels approximating in vivo biliary bile acid concentration. Furthermore, nearly all of the taurocholate infused was ultimately recovered in the bile, indicating that the perfused rat liver was capable of excreting the added bile salt.

The effect of the bile salt infusion on the BSP transport maxima ( $\mathrm{Tm})$ is illustrated in the middle graph of Fig. 1. Although the maximum level of BSP excretion was reached at $2 \mathrm{hr}$ whether or not taurocholate was infused, the $\mathrm{Tm}$ averaged $15.8 \pm 4.16 \mu \mathrm{g} / \mathrm{min}$ per $\mathrm{g}$. liver in controls but increased to $21.57 \pm 3.0 \mu \mathrm{g} / \mathrm{min}$ per g liver during taurocholate infusion. This difference was statistically significant $(P<0.05)$. Moreover, the $\mathrm{Tm}$ declined progressively in the controls after $2 \mathrm{hr}$, but remained elevated during bile salt infusion. The difference in $\mathrm{Tm}$ was highly significant $(P<0.001)$ at $3 \mathrm{hr}$, and remained so for the last $2 \mathrm{hr}$ of perfusion.

To further confirm that the decline in $\mathrm{Tm}$ noted in controls was related to low bile salt excretion and diminished bile flow, sodium taurocholate was infused in five additional experiments during the 4th $\mathrm{hr}$ of the perfusion. The results of a representative experiment are illustrated in Fig. 2. Although the magnitude of the response differed in each of the studies, bile volume and the BSP Tm always rose above levels in the preceding half-hour bile collection.

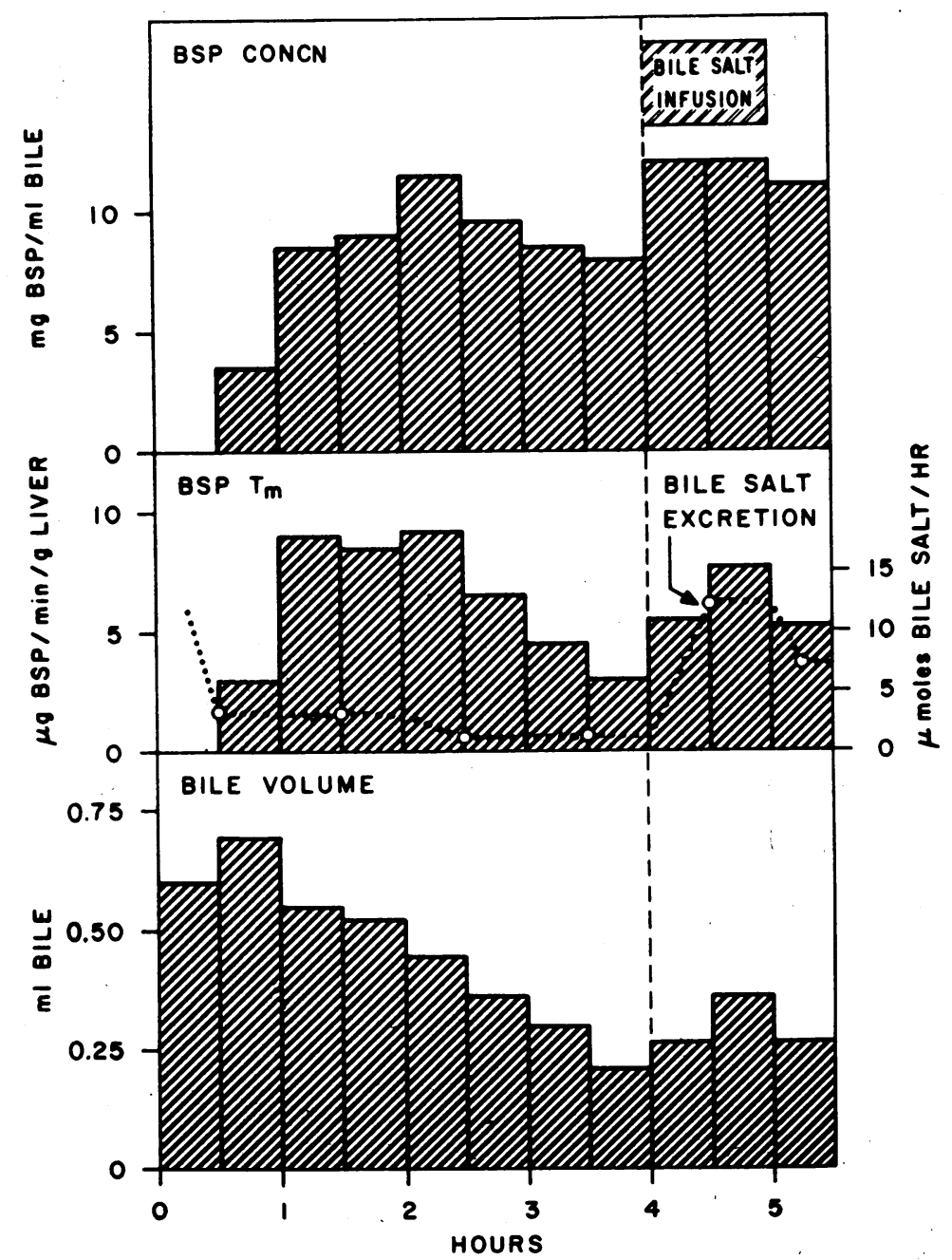

FIGURE 2 A representative study of the enhancement of the BSP Tm when bile salts were infused during the period of declining bile flow and BSP transport. Biliary bile salt excretion is expressed as $\mu$ moles bile salt excreted per hour. 
The concentration of BSP in bile during control and taurocholate infusion experiments is illustrated in Fig. 3 . During the period of peak bile flow $(1.5-2 \mathrm{hr})$, the concentrations of BSP in bile were identical whether or not bile salts were infused. Thereafter, the concentration in controls fell slightly below that of the taurocholate-infused group, although the differences were not statistically significant except for the last hour of the perfusion.

The relationship between bile flow and the biliary excretion of bile salts and BSP. Since the previous studies suggested that bile salts regulated BSP transport by modifying the rate of bile flow, additional experiments were designed to test this hypothesis. Bile flow was altered by changing the temperature of the perfusate while maintaining a constant infusion of taurocholate. This enabled us to establish more clearly whether bile salts affected BSP transport by a direct effect on cellular metabolism or by acting as a choleretic. Results of two representative experiments are illustrated in Figs. 4 and 5. Essentially identical findings were obtained in the other studies. When the perfusate temperature was maintained at $40^{\circ} \mathrm{C}$, both bile flow and the BSP Tm increased above the values noted in previous studies at $37^{\circ} \mathrm{C}$. Both fell rapidly in parallel when the temperature was reduced to $30^{\circ} \mathrm{C}$ and again returned to the original level when the perfusate was rewarmed.

In contrast, biliary bile salt concentration varied inversely with bile flow and BSP Tm under these conditions. Accordingly, since biliary BSP concentration remained relatively constant, BSP transport was correlated with bile flow rather than with biliary bile acid excretion.

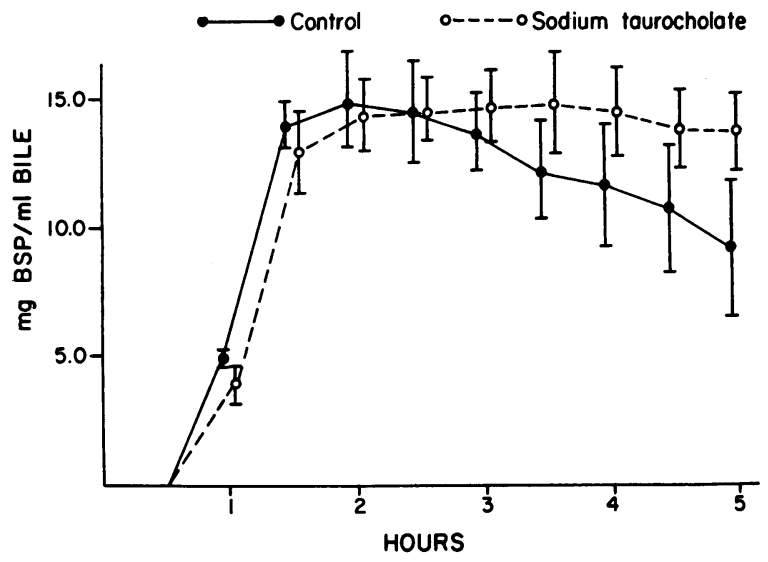

Figure 3 The effect of bile salt infusion on the concentration of BSP in bile. The mean and standard deviation of the concentration of BSP in each half hour collection of bile was determined in five controls and in five studies during the infusion of sodium taurocholate. The difference in the means was not significant except for the concentrations determined at $5 \mathrm{hr}(P<0.02)$.

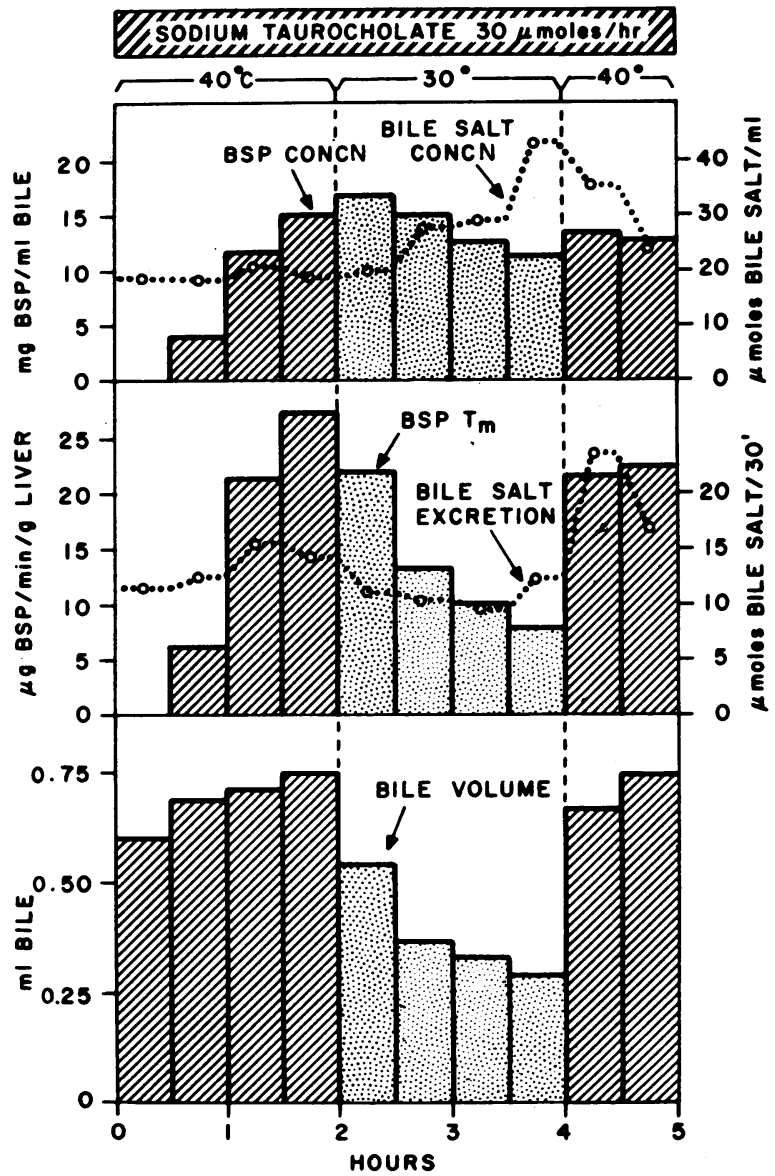

FIgURE 4 The effect of changing the rate of bile flow on the biliary excretion of BSP and bile salts in the perfused rat liver. Bile flow was controlled by altering the temperature of the perfusate as indicated in the figure. Sodium taurocholate was infused at a constant rate of $30 \mu \mathrm{moles} / \mathrm{hr}$ for the duration of the study. BSP concentration, BSP Tm, and bile volume are represented for each half hour by the bar graph. Bile salt concentration and excretion are represented by the dotted lines whose ordinates are at the right of the figure. The change in the BSP $\mathrm{Tm}$ was proportional to the change in bile flow rather than the excretion of bile salts.

In the experiment illustrated in Fig. 5, the temperature of the perfusate was maintained at $40^{\circ} \mathrm{C}$ for $2 \mathrm{hr}$ and then was reduced to $25^{\circ}-30^{\circ} \mathrm{C}$ for $3 \mathrm{hr}$. As in the previous experiments, bile flow and BSP Tm fell during hypothermia. Moreover, enhancing bile salt excretion by doubling the infusion rate of bile acid during the $3 \mathrm{rd} \mathrm{hr}$ of hypothermia did not increase either bile flow or BSP Tm.

BSP conjugating activity. The effect of infusions of taurocholate or saline on the activity of the BSP-conjugating enzyme in the perfused rat liver is illustrated in Fig. 6. Enzyme activity in 10 nonperfused normal rats 


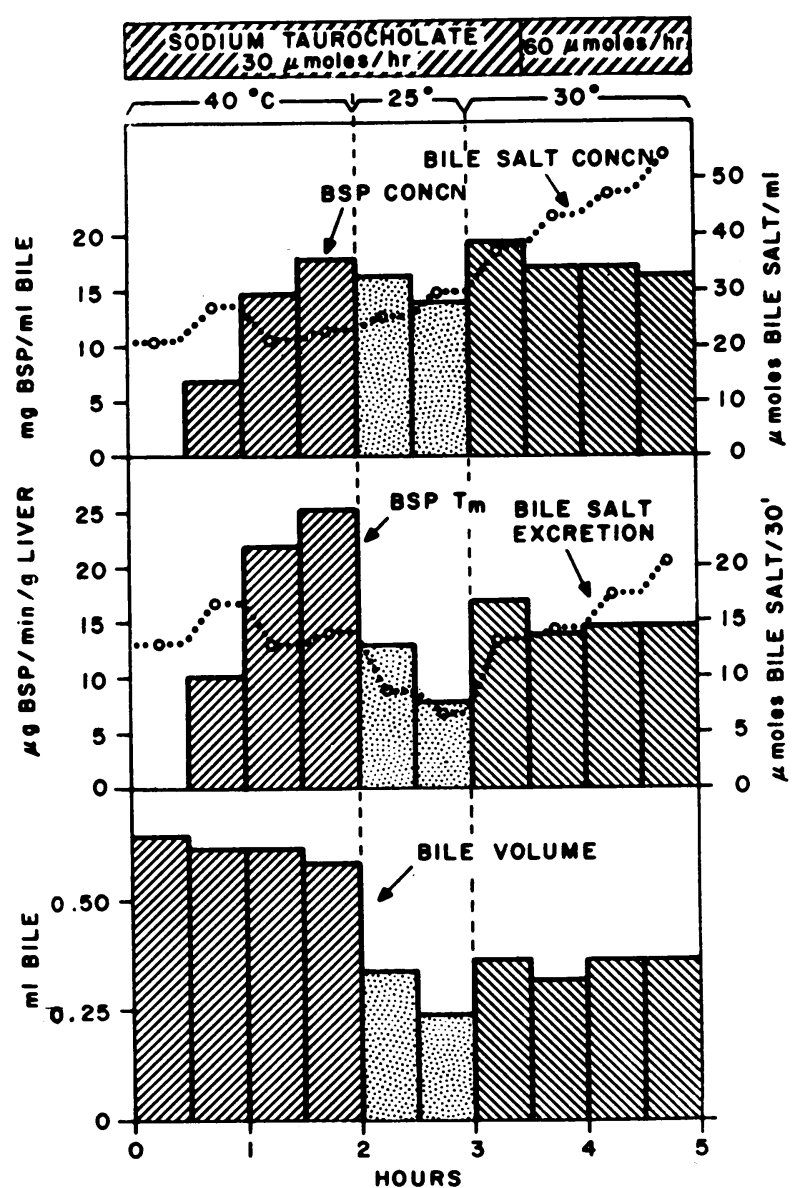

FIGURE 5 The effects of maintaining hypothermia while doubling the rate of bile salt excretion on bile flow, BSP $\mathrm{Tm}$, and biliary excretion of bile salts. BSP transport continued to parallel bile flow rather than bile salt excretion.

averaged $14.6 \pm 1.7 \mathrm{mg} \mathrm{BSP} / \mathrm{g}$ liver per $5 \mathrm{~min}$. Although a slight decline in activity was noted during both the saline and taurocholate infusions, enzyme activity from the perfused liver was within the normal range for the entire course of each study. In contrast, the addition of increasing amounts of bile salt to the in vitro assay progressively inhibited BSP-glutathione conjugation (Fig. 7). The minimal concentration of bile salt required for inhibition was several orders of magnitude in excess of the presumed normal portal vein bile salt concentration of $10^{-4}$ mole/liter.

$B S P$ metabolites in bile. During taurocholate infusion, the proportion of unconjugated BSP in bile was increased and ranged from 11.0 to $15.5 \%$ during the 2nd $\mathrm{hr}$ and from 10 to $21 \%$ during the 4 th $\mathrm{hr}$ (Fig. 8). Measurement of unconjugated BSP in bile at respective times in the control studies ranged from only 2 to $4 \%$ and from 2.4 to $8.6 \%$.

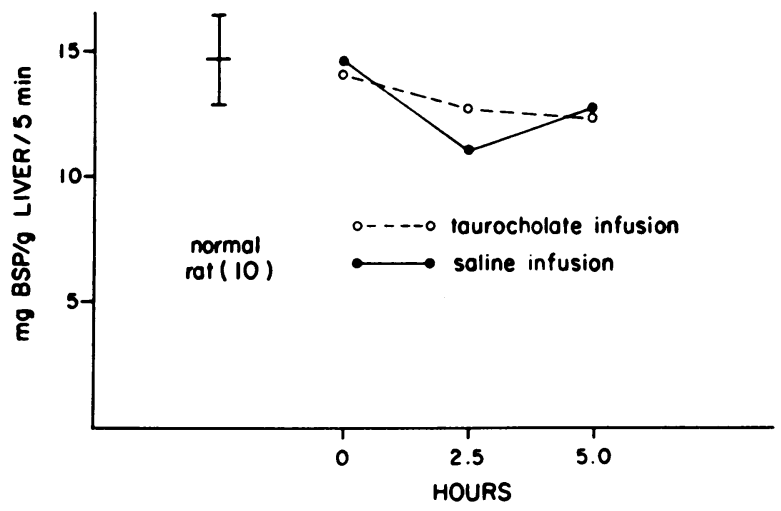

FIGURE 6 The in vitro BSP-glutathione conjugating activity (mean and standard deviation) in 10 normal nonperfused rat livers compared to that in perfused rat livers during infusion of taurocholate or saline. Enzyme activity was determined in the perfused rat liver at $0,2.5$, and $5 \mathrm{hr}$.

Hepatic uptake and hepatic content of BSP. Although declining slightly during the course of all perfusions, the rate of hepatic BSP removal from plasma was enhanced above control values during the taurocholate infusion, both at 2.5 and $5 \mathrm{hr}$ (Fig. 9). However, despite the increased uptake, the fraction of infused BSP stored in the liver was lower than in control experiments (Fig. 10).

\section{DISCUSSION}

The isolated perfused liver provides a unique model for the study of BSP metabolism, since it avoids problems encountered in the intact animal related to peripheral uptake, enterohepatic circulation and urinary losses of dye. In addition, hormonal and neurogenic effects are eliminated, particularly the endogenous release of secretin, which influences bile production and solute concentration (29). Furthermore, the technique enabled us to compare a state of low bile salt excretion with one closely resembling that of the intact rat.

As previously shown by Brauer and Pessotti, infusion of bile salt increases the output of bile by the isolated perfused liver (30). In addition, the present experiments demonstrate that the progressive decline in bile flow observed in such preparations can be correlated with a decrease in the biliary excretion of bile salts, and can be prevented by infusing taurocholate. This is in agreement with observations of Preisig, Cooper, and Wheeler, that production of bile is related to the rate of hepatic bile salt excretion (31).

Moreover, the present studies show that the isolated perfused liver is capable of maintaining a level of BSP transport comparable to that of the intact rat when the biliary concentration of bile salt is maintained at physiologic levels. Thus, the BSP Tm, in our perfused livers,

Bile Salts, Bile Flow, and BSP Metabolism 
based on the body weight of donor rats, was found to be $0.8 \pm 0.09 \mathrm{mg} / \mathrm{min}$ per $\mathrm{kg}$ rat, whereas those reported for the intact rat by Combes (2) and Klaassen and Plaa (27) were $1.0 \mathrm{mg}$ and $0.9 \mathrm{mg} / \mathrm{min}$ per $\mathrm{kg}$ rat, respectively.

The results of the present study indicate that bile salts have a significant influence on the hepatic metabolism of BSP. The first effect observed after taurocholate infusion was an apparent increase in the hepatic uptake of the dye (Fig. 9). Although little is known about the mechanism of hepatic uptake, BSP is tightly bound to albumin and must be removed in the process of transfer from plasma to hepatic binding proteins. Since Andrews and Richards have shown that bile salts have only a weak effect on the BSP-albumin bond (32), it is unlikely that the increase in uptake was attributable to dissociation of the BSP-albumin complex. Furthermore, in preliminary studies we have been unable to demonstrate an increased hepatic uptake of BSP by rat liver slices in albumin and Krebs-Ringer bicarbonate buffer when incubated with bile salts (unpublished findings). These observations suggest that the enhanced uptake observed in our perfusion experiments was not due to a change in either the BSPalbumin bond or in the permeability or avidity of hepatic cells for BSP. The alternative hypothesis, that taurocholate inhibited the reflux of BSP from the hepatic cells into the perfusate, cannot be excluded with certainty. However, since the biliary excretion of BSP was increased by taurocholate (Fig. 1), and the hepatic content of BSP in taurocholate-treated livers was less than that of control livers at any time after the onset of the BSP infusion (Fig. 10), it seems likely that the enhanced hepatic uptake of BSP from plasma was secondary to the more rapid transit of dye through the liver.

The major effect of sodium taurocholate on BSP metabolism was to enhance the BSP transport maximum. Similar observations in the intact animal have recently been reported by O'Maille, Richards, and Short (18) and Ritt and Combes in the dog (19), and by Gronwell and Cornelius in the sheep (20). Since bile salt increased the volume of bile secreted but did not enhance BSP concentration in our experiments, it would appear that the increase in BSP $\mathrm{Tm}$ was attributable to augmented bile flow. Thus, the peak concentartion of BSP in bile was identical in controls and in livers perfused with taurocholate $(14.8 \pm 1.9$ and $14.7 \pm 2.0 \mathrm{mg} / \mathrm{ml}$, respectively), so that the increase in the transport of BSP was due entirely to the greater volume of bile flow during the taurocholate-induced choleresis. These results are similar to those of O'Maille et al., who noted no increase in the biliary concentartion of BSP when the Tm was enhanced 3 -fold by taurocholate infusion in the dog (18). Furthermore, in our studies, the decrease in bile flow that accompanied a reduction in bile salt excretion resulted in a progressive fall in the transport maximum. BSP concentration diminished only slightly so that the decline in transport was almost completely accounted for by the reduction in bile flow.

These data, as well as those of O'Maille et al. (18), suggest that the concentration of BSP in canilicular bile has an upper limit which remains relatively constant over a wide range of bile production. If the concentra-

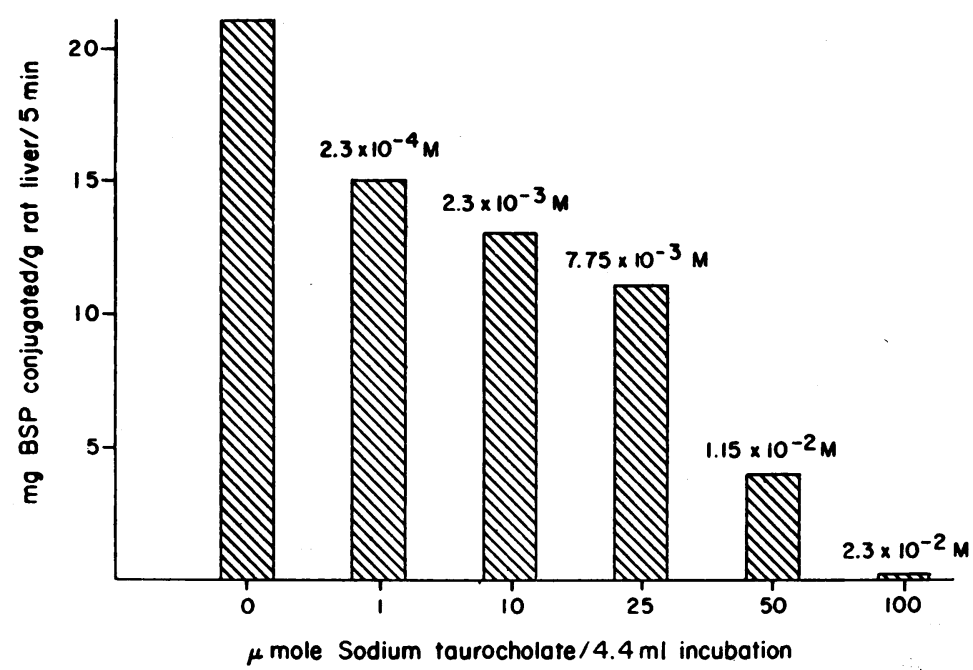

FIGURE 7 The in vitro effect of increasing concentrations of sodium taurocholate on BSP-glutathione-conjugating enzyme activity of rat liver supernatents $(104,000 \mathrm{~g})$. The molar concentration of bile salts in the incubation is given above the solid bar. 
tion of BSP within the canilicular bile is regulated by an energy-dependent liver cell-bile concentration gradient, as previously suggested by O'Maille et al. (18), then the ability to concentrate BSP in bile may be the major limiting factor in the rate of BSP transport. If BSP concentration is limited, then changes in bile flow would independently effect proportional changes in the BSP transport maximum. The present data suggest therefore, that the BSP Tm is determined by two independent processes: a limited concentrating capacity for biliary BSP and the rate of bile production.

Although the results of our experiments suggest that bile salts affect the BSP Tm by promoting bile flow rather than by enhancing the BSP concentrating capacity, it is conceivable that they enhance BSP transport by other means such as increasing membrane permeability, or stimulating a specific transport system. These possibilities seem unlikely, however, since the experiments illustrated in Figs. 4 and 5 indicated that BSP transport also paralleled temperature-regulated changes in bile flow rather than the concentration of biliary bile salts.

For example, BSP transport continued to be determined by the reduced rate of bile flow during hypothermia even though the biliary concentration of bile salts was increased by doubling the rate of taurocholate

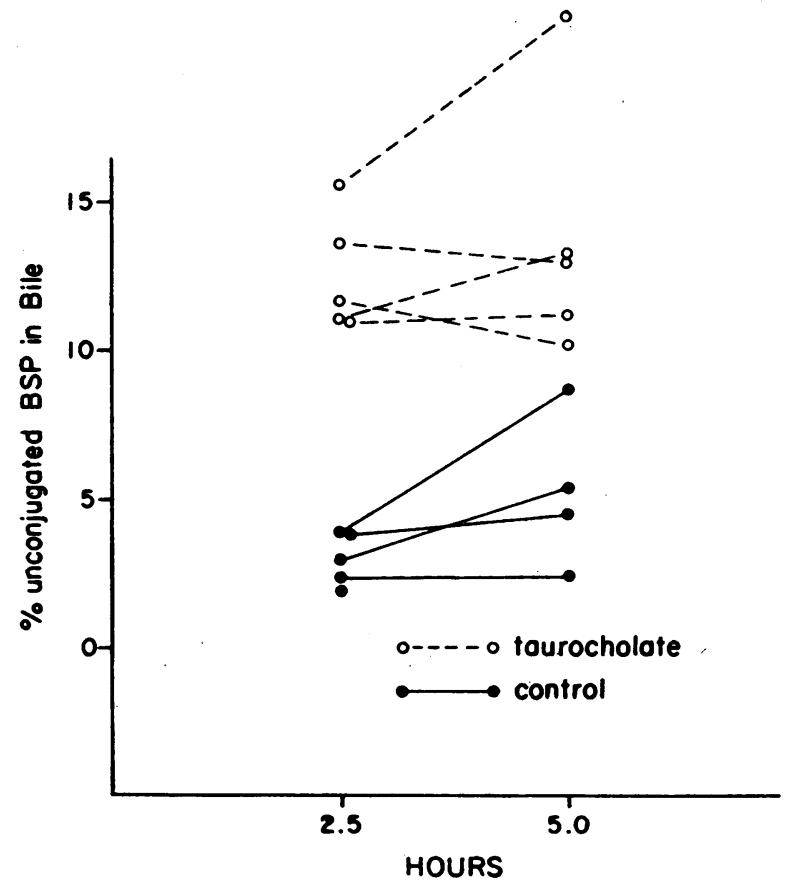

FIGURE 8 The effect of bile salts on the excretion of unconjugated BSP in bile. Measurements were made on bile obtained from the perfused rat liver at 2.5 and $5 \mathrm{hr}$ in five control studies and five studies during infusion of sodium taurocholate.

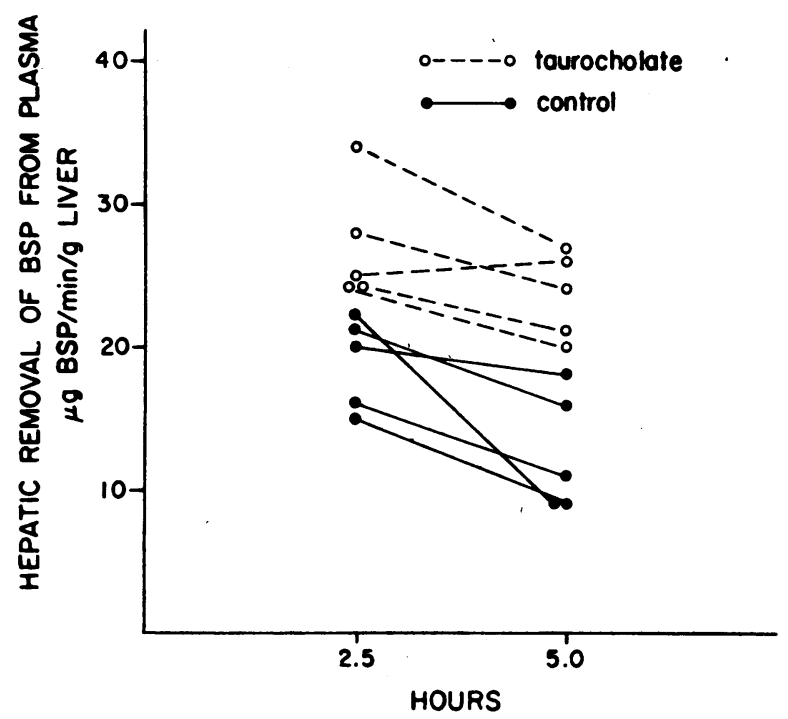

Figure 9 The effect of bile salts on the rate of removal of BSP from the perfusate by the perfused rat liver. Measurements were made in five control studies and five studies during sodium taurocholate infusion. Each point represents the value obtained in a single perfusion experiment.

infusion (Fig. 5). During these experiments, the biliary concentration of taurocholate approached the limit reported for the intact rat by Javitt and Harkavy ( $74 \pm 9$ mmoles/liter) (33) but the infused bile salt was un-

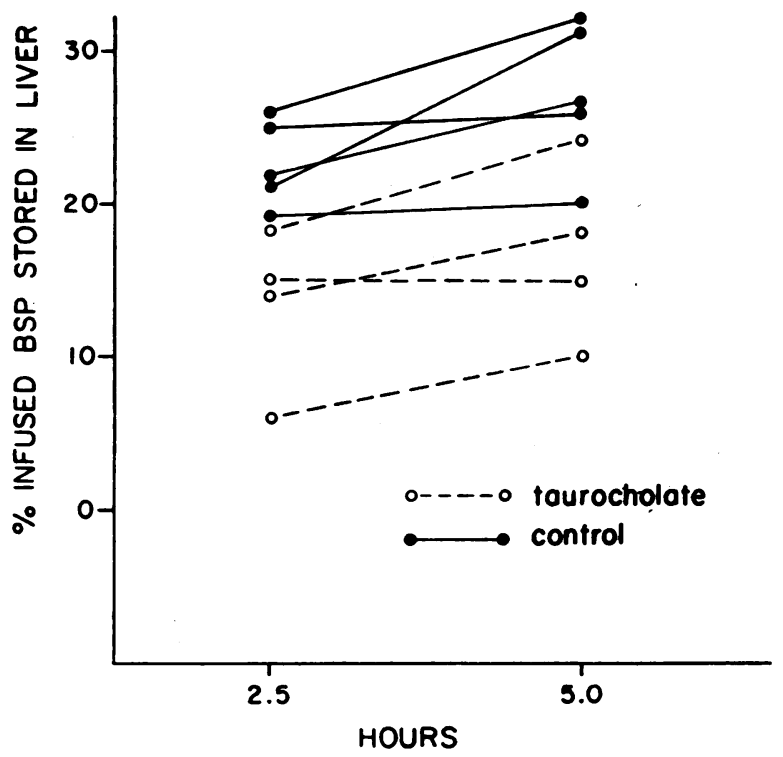

FIgure 10 The effect of bile salts on BSP stored in the perfused rat liver. Measurements were made at 2.5 and $5 \mathrm{hr}$ and expressed as the per cent infused BSP stored in the liver. Each point represents the value obtained in a single perfusion experiment.

Bile Salts, Bile Flow, and BSP Metabolism 
able to increase the BSP $\mathrm{Tm}$ even though presumably able to alter membrane-transport systems.

It might be argued, however, that the normal effect that bile salts exert on membranes to promote water or electrolyte secretion would be reduced during hypothermia, and consequently the observed changes in BSP $\mathrm{Tm}$ and bile flow might both be related to a bile salttemperature-dependent membrane effect. This seems very unlikely, since earlier work by Brauer, Leong, and Holloway (34) clearly demonstrated that bile production is temperature dependent in the perfused rat liver when bile salts are not infused into the perfusate. Since liver perfusion leads to a rapid depletion in the level of bile salt concentration (Fig. 1), it is apparent that the temperature dependency of bile production does not primarily involve the function of bile salts and is more likely a direct effect of temperature on bile secretory metabolism. Furthermore, if hypothermia altered a temperature-dependent membrane-transport system, the biliary concentration of BSP or other transported solutes such as bile salts or bilirubin might be expected to decline. Extensive studies by Vanlerenberghe (35) during hypothermia in the perfused rat liver indicate that this does not occur and argue for two separate secretion mechanisms, one for the liquid phase and the other for dissolved substances. The results of these studies are consistant with our own conclusions that BSP transport is reduced during hypothermia because the volume of bile is diminished independently of the secretion of bile salts, thereby minimizing the importance of a bile salt-dependent membrane effect.

Because taurocholate increased unconjugated BSP excretion preferentially (Fig. 8), the possibility must be considered that a carrier or transport system for this form of the dye was affected. However, it is more likely that the relative increase in unconjugated BSP in bile was attributable to a reduction in back diffusion as bile flow increased. Since unconjugated BSP is more lipid soluble than its conjugates, it might be anticipated that the former would back diffuse from the canaliculi to the hepatic cells more readily than the latter, and, hence, would be affected to a greater extent by rapid flow of bile that would reduce the period of its contact with the hepatocyte.

Since conjugation of BSP enhances its rate of excretion in bile $(2,17)$ bile salts might presumably increase BSP Tm by stimulating the BSP-glutathione conjugating system. However, in the present studies, BSP-glutathione conjugating activity remained stable throughout the 5-hr control perfusions, despite a decline in BSP Tm, and was not enhanced by taurocholate infusion, which increased BSP $\mathrm{Tm}$. Indeed, in our in vitro experiments, high concentrations of taurocholate appeared to inhibit the conjugating system (Fig. 7).
Thus, the results of the present study suggest that bile salts do not enhance the transport of BSP by altering membrane permeability, by stimulating a transport system, or by influencing BSP-glutathione conjugation.

Rather, it is clear that the rate of bile flow is an important determinant of the BSP $\mathrm{Tm}$ and that bile salts enhance the $\mathrm{Tm}$ when they are able to function as a choleretic.

Since bile salts are believed to be a major stimulus for bile production, it is not unreasonable to suggest that abnormalities in bile salt excretion may under some conditions result in changes in bile flow and account for abnormalities in BSP Tm. Further studies will be necessary to establish whether or not the biliary transport of other anions, such as bilirubin, may also have a limiting concentration in bile and be affected by changes in the rate of bile flow.

\section{ACKNOWLEDGMENTS}

We gratefully acknowledge the helpful suggestions of Dr. Nicholas Alexander and the expert technical assistance of Misses Rose Marie Moquin and Barbara Gillette.

This work was supported by Research Grant AM 05966-07 and Training Grant AM 5180-10 from the National Institutes of Health, U. S. Public Health Service.

\section{REFERENCES}

1. Brauer, R. W., and R. L. Pessotti. 1950. Hepatic uptake and biliary excretion of bromsulphthalein in the dog. Amer. J. Physiol. 162: 565.

2. Combes, B. 1965. The importance of conjugation with glutathione for sulfobromophthalein sodium (BSP) transfer from blood to bile. J. Clin. Invest. 44: 1214.

3. Grodsky, G. M., J. V. Carbone, and R. Fanska. 1961. Biosynthesis of a sulfobromophthalein mercaptide with glutathione. Proc. Soc. Exp. Biol. Med. 106: 526.

4. Javitt, N. B., H. O. Wheeler, K. J. Baker, O. L. Ramos, and S. E. Bradley. 1960. The intrahepatic conjugation of sulfobromophthalein and glutathione in the dog. J. Clin. Invest. 39: 1570.

5. Wirts, C. W., Jr., and A. Cantarow. 1942. A study of the excretion of bromsulphthalein in the bile. Amer. J. Dig. Dis. 9: 101.

6. Wheeler, H. O., R. M. Epstein, R. R. Robinson, and E. S. Snell. 1960. Hepatic storage and excretion of sulfobromophthalein sodium in the dog. J. Clin. Invest. 39: 236.

7. Wheeler, H. O., J. I. Meltzer, and S. E. Bradley. 1960. Biliary transport and hepatic storage of sulfobromophthalein sodium in the unanesthetized dog, in normal man, and in patients with hepatic disease. J. Clin. Invest. 39: 1131 .

8. Combes, B. 1964. Excretory function of the liver. In The Liver. C. Rouiller, editor. Academic Press Inc., New York. 2: 1 .

9. Sperber, I. 1959. Secretion of organic anions in the formation of urine and bile. Pharmacol. Rev. 11: 109.

10. Williams, R., R. Preisig, J. Sweeting, and S. E. Bradley. 1963. Storage and transport of bromsulphthalein in hepatitis and other liver diseases. Gut. 4: 89.

\section{J. L. Boyer, R. L. Scheig, and G. Klatskin}


11. Schoenfield, L. J., W. T. Foulk, and H. R. Butt. 1964. Studies of sulfobromophthalein sodium (BSP) metabolism in man. I. In normal subjects and patients with hepatic disease. J. Clin. Invest. 43: 1409.

12. Combes, B., H. Shibata, R. Adams, B. D. Mitchell, and V. Trammell. 1963. Alterations in sulfobromophthalein sodium-removal mechanisms from blood during normal pregnancy. J. Clin. Invest. 42: 1431.

13. Roberts, R. J., C. D. Klaassen, and G. L. Plaa. 1967. Maximum biliary excretion of bilirubin and sulfobromophthalein during anesthesia-induced alteration of rectal temperature. Proc. Soc. Exp. Biol. Med. 125: 313.

14. Mueller, M. N., and A. Kappas. 1964. Estrogen pharmacology. I. The influence of estradiol and estriol on hepatic disposal of sulfobromophthalein (BSP) in man. J. Clin. Invest. 43: 1905.

15. Scherb, J., M. Kirschner, and I. Arias. 1963. Studies of hepatic excretory function. The effect of $17 \alpha$-ethyl19-nortestosterone on sulfobromphthalein sodium (BSP) metabolism in man. J. Clin. Invest. 42: 404.

16. Schoenfield, L. J., and W. T. Foulk. 1964. Studies of sulfobromophthalein sodium (BSP) metabolism in man. II. The effect of artificially induced fever, norethandralone (Nilevar) and iopanoic acid (Telapaque). J. Clin. Invest. 43: 1419.

17. Philp, J. R., G. M. Grodsky, and J. V. Carbone. 1961 Mercaptide conjugation in the uptake and secretion of sulfobromophthalein. Amer. J. Physiol. 200: 545.

18. O'Maille, E. R. L., T. G. Richards, and A. H. Short. 1966. Factors determining the maximal rate of organic anion secretion by the liver and further evidence of the hepatic site of action of the hormone secretin. J. Physiol. (London). 186: 424.

19. Ritt, D. J., and B. Combes. 1967. Enhancement of apparent excretory maximum of sulfobromophthalein sodium (BSP) by taurocholate and dehydrocholate. $J$. Clin. Invest. 46: 1108. (Abstr.)

20. Gronwall, R., and C. E. Cornelius. 1966. Biliary excretion of sulfobromophthalein in sheep. Fed. Proc. 25: 576 (Abstr.)

21. Miller, L. L., C. G. Bly, M. L. Watson, and W. F. Bale. 1951. The dominant role of the liver in plasma protein synthesis. J. Exp. Med. 94: 431.

22. Mainland, D. 1963. Elementary medical statistics. W. B. Saunders Company. Philadelphia. 2nd edition. 290.
23. Seligson, D., J. Marino, and E. Dodson. 1957. Determination of sulfobromophthalein in serum. Clin. Chem. 3: 638 .

24. Javitt, N. B., and S. Emerman. 1968. Effect of sodium taurolithocholate on bile flow and bile acid excretion. J. Clin. Invest. 47: 1002.

25. Iwata, T., and K. Yamasaki. 1964. Enzymatic determination and thin layer chromatography of bile acids in blood. J. Biochem. (Tokyo). 56: 424.

26. Goldstein, J., and B. Combes. 1966. Spectrophotometric assay of the liver enzyme that catalyzes sulfobromophthalein-glutathione conjugation. J. Lab. Clin. Med. 67: 863.

27. Klaassen, C. D., and G. L. Plaa. 1967. Species variation in metabolism, storage, and excretion of sulfobromophthalein. Amer. J. Physiol. 213: 1322.

28. Whelan, F. J., and G. L. Plaa. 1963. The application of thin layer chromatography to sulfobromophthalein metabolism studies. Toxicol. Appl. Pharmacol. 5: 457.

29. Wheeler, H. O., and P. L. Mancusi-Ungaro. 1966. Role of bile ducts during secretin choleresis in dogs. Amer. J. Physiol. 210: 1153 .

30. Brauer, R. W., and R. L. Pessotti. 1952. The effect of choleretic and of hydrochloleretic agents on bile flow and bile solids in the isolated perfused liver. Science (Washington). 115: 142.

31. Preisig, R., H. L. Cooper, and H. O. Wheeler. 1962. The relationship between taurocholate secretion rate and bile production in the unanesthetized dog during cholinergic blockade and during secretin administration. J. Clin. Invest. 41: 1152.

32. Andrews, W. H. H., and T. G. Richards. 1960. The activity of bile salts and certain detergents on the hepatic storage and protein-binding of sulphobromophthalein. Quart. J. Exp. Physiol. 45: 275.

33. Javitt, N. B., and M. Harkavy. 1969. Ethinyl estradiol induced cholestasis in female Wistar rats. Gastroenter ology. 56: 400. (Abstr.)

34. Brauer, R. W., G. F. Leong, and R. J. Holloway. 1954 Mechanics of bile secretion. Effect of perfusion pressure and temperature on bile flow and bile secretion pressure. Amer. J. Physiol. 177: 103.

35. Vanlerenberghe, J. 1965. The effects of hypothermia on biliary function. In The Biliary System. W. Taylor, Blackwell Scientific Publications Ltd., Oxford. 263. 